\title{
Dynamics of multi-point singular fifth-order Lane-Emden system with neuro-evolution heuristics
}

\author{
zulqurnain sabir ${ }^{1}$, Mohamed Ali², Muhammad Asif Zahoor Raja ${ }^{3}$, rahma sadat ${ }^{4}$, and D. \\ Baleanu $^{5}$
}

${ }^{1}$ Hazara University

${ }^{2}$ Banha University

${ }^{3}$ COMSATS Institute of Information Technology - Attock

${ }^{4}$ Zagazig University Faculty of Engineering

${ }^{5}$ Cankaya University

July 5,2020

\begin{abstract}
Aim of the presented study is to investigate the numerical solution of fifth-order nonlinear Lane-Emden (LE) based singular system at the origin with different shape factors developed on the analogous pattern of standard second order LE equations. The stochastic neuro-evolution computing is exploited for numerical outcomes by using the artificial neural networks (ANNs) for applicable mapping and learning of decision variables with integrated meta-heuristics of genetic algorithms (GAs) for global search aided with the rapid local search of active-set (AS) i.e., ANN-GA-AS algorithm. The designed numerical computing approach ANN-GA-AS implemented effectively for solving fifth-order nonlinear LE singular system and results of statistical assessments further authenticate the accuracy, convergence, and stability.
\end{abstract}

\section{Hosted file}

Dumitru Baleanu - 1.docx available at https://authorea.com/users/339913/articles/467036dynamics-of-multi-point-singular-fifth-order-lane-emden-system-with-neuro-evolutionheuristics 


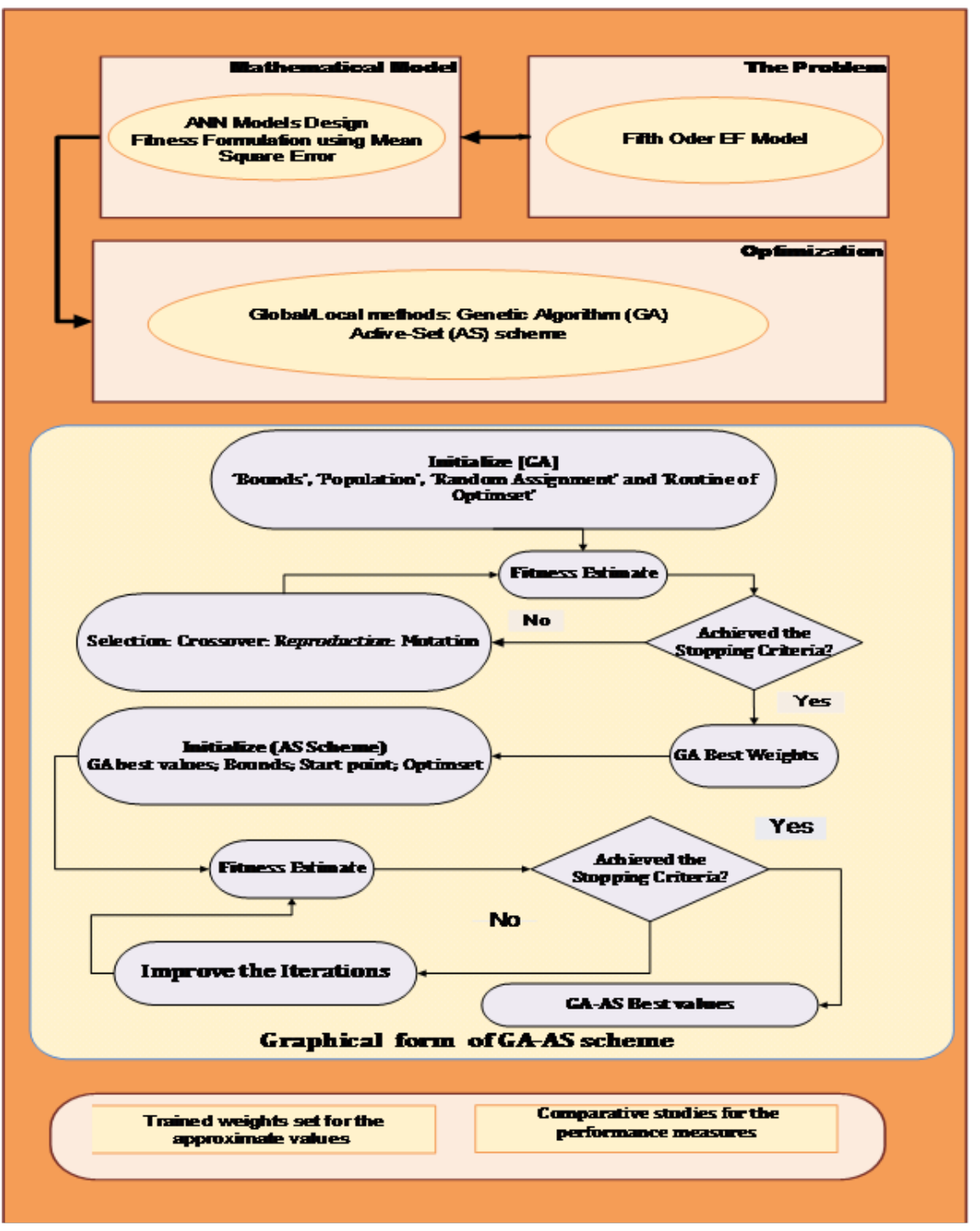

Fes 1: Framework of the designed ANN-GA-AS scheme for solving the fith-order FF model 

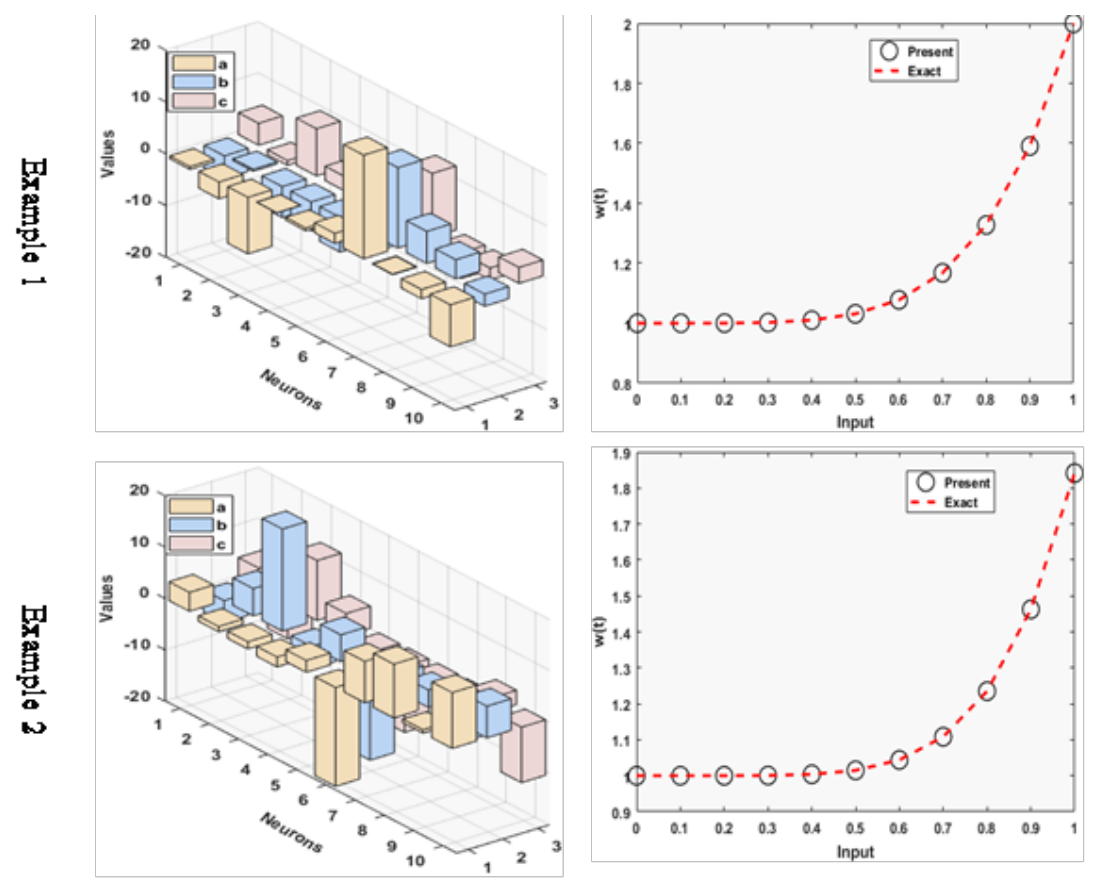

Fig .2. Set of weights and comparison of exact/proposed results for both the examples of fifth-order LE model of type 1 . 


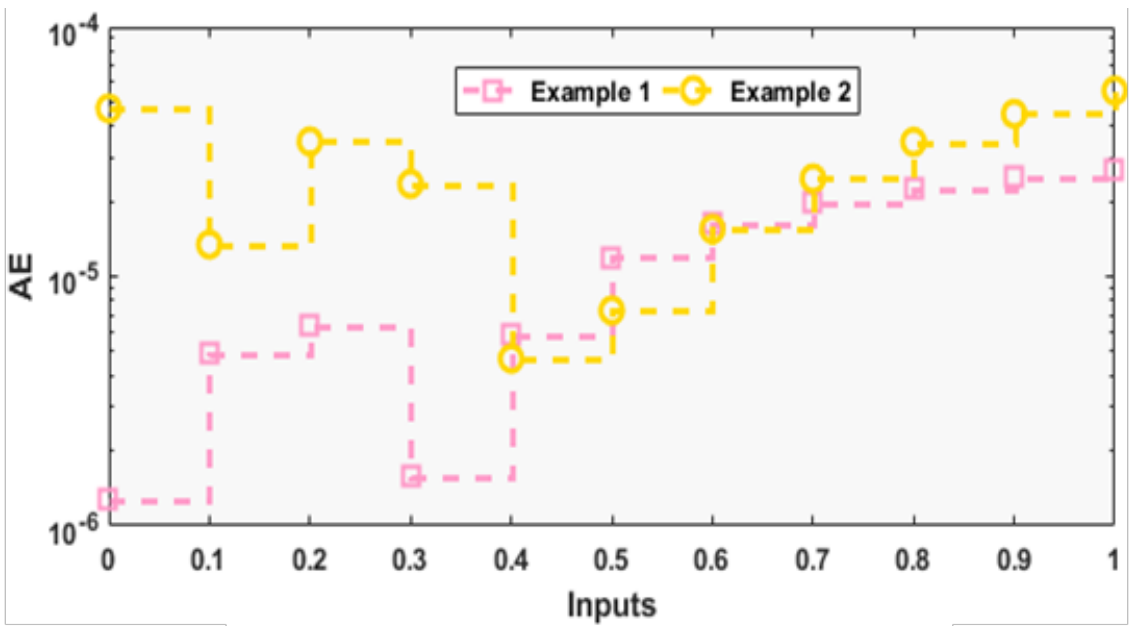

(a) $\mathrm{AE}$ for both the examples of fifth-order LE model of type 1

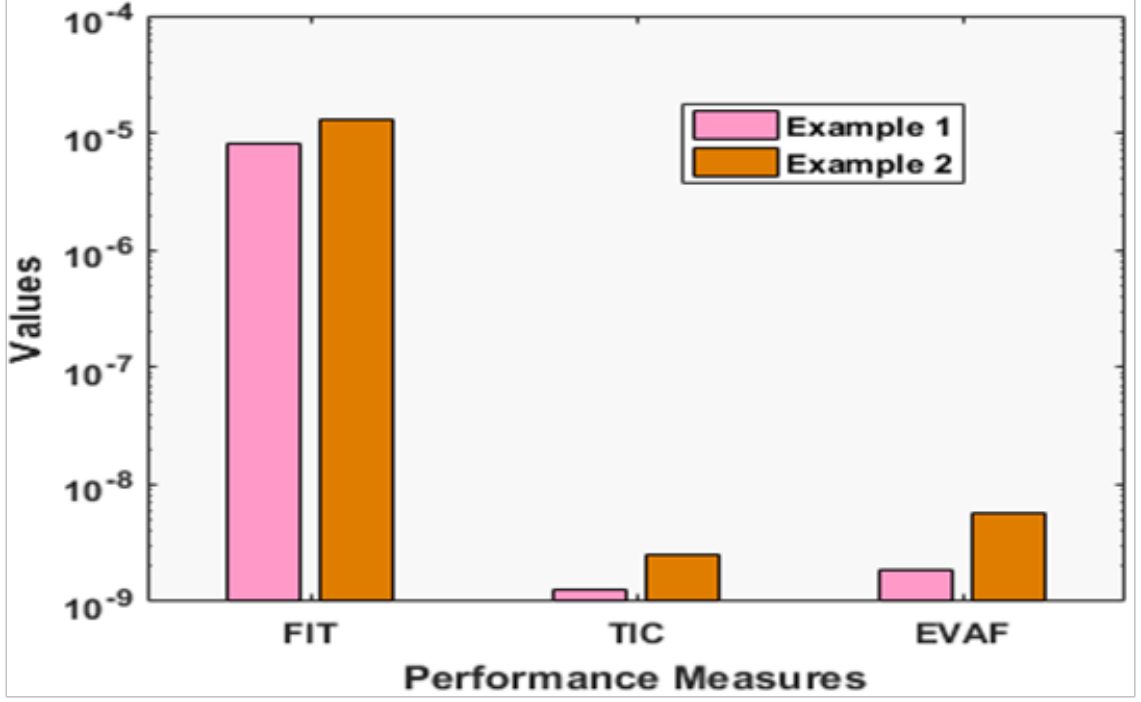

(b) Perfomance indices for both the Framples of the type 1

F. 3. $A E$ and performance indices for both the examples of fifth-order LE model of type 1. 